\title{
Metal particles produced by laser ablation for ICP-MS measurements
}

Lawrence Berkeley National Laboratory, Berkeley, CA 94720, USA

*Corresponding author. Tel.: +1-510-486-4258; fax: +1-510-483-7303. rerusso@1bl.gov

Jhanis J. Gonzalez, Chunyi Liu, Sy-Bor Wen, Xianglei Mao and Richard E. Russo

\begin{abstract}
Pulsed laser ablation (266nm) was used to generate metal particles of $\mathrm{Zn}$ and $\mathrm{Al}$ alloys using femtosecond (150 fs) and nanosecond (4 ns) laser pulses with identical fluences of $50 \mathrm{~J} \mathrm{~cm}^{-2}$. Characterization of particles and correlation with Inductively Coupled Plasma Mass Spectrometer (ICP-MS) performance was investigated. Particles produced by nanosecond laser ablation were mainly primary particles with irregular shape and hard agglomerates (without internal voids). Particles produced by femtosecond laser ablation consisted of spherical primary particles and soft agglomerates formed from numerous small particles. Examination of the craters by white light interferometric microscopy showed that there is a rim of material surrounding the craters formed after nanosecond laser ablation. The determination of the crater volume by white light interferometric microscopy, considering the rim of material surrounding ablation craters, revealed that the volume ratio (fs/ns) of the craters on the selected samples was approximately 9 (Zn), 7 (NIST627 alloy) and 5 (NIST1711 alloy) times more ablated mass with femtosecond pulsed ablation compared to nanosecond pulsed ablation. In addition, an increase of $\mathrm{Al}$ concentration from 0 to $5 \%$ in $\mathrm{Zn}$ base alloys caused a large increase in the diameter of the particles, up to $65 \%$ while using nanosecond laser pulses. When the ablated particles were carried in argon into an ICP-MS, the $\mathrm{Zn}$ and Al signals intensities were greater by factors of $\sim 50$ and $\sim 12$ for fs $v s$. ns ablation. Femtosecond
\end{abstract}


pulsed ablation also reduced temporal fluctuations in the ${ }^{66} \mathrm{Zn}$ transient signal by a factor of ten compared to nanosecond laser pulses.

\section{Introduction}

The aerosol size and size distributions are central topics in current laser ablation ICP-MS research. The particle size is a primary parameter that determines the entrainment, transport efficiency, composition, and decomposition of laser-ablated particles in the ICP [1-5]. To optimize particle size and the size distribution for laser ablation chemical analysis, it is necessary to identify and study particle growth mechanisms [6;7]. A schematic representation of particle formation from vapor is presented in figure 1. At high temperatures (but below the material boiling temperature), primary particles are formed by nucleation followed by condensation. Afterwards, collision of primary liquid particles leads to coalescence and an increase in the primary size (collision-coalesce process). As the temperature decreases, coalescence ceases and colliding particles tend to form hard and soft agglomerates which can continue to grow by a cluster-cluster collision process [8-11]. Experimental conditions in which any of these processes is favored will establish the final particle size and shape.

The characteristics of particles generated by laser ablation, namely, number density, composition, shape and size distribution are dependent on parameters such as those that influence the amount of ablated mass: laser power density, beam diameter and profile, wavelength, etc. Parameters that influence the plasma properties and evolution (gas environment, pressure, etc), and sample chemical and physical properties are important as well $[2 ; 4 ; 5 ; 12-14]$. 
It has been demonstrated that experimental conditions in laser ablation studies could be established in order to customize particle size and size distribution [15-17]. However one question that immediately emerges is; are ideal laser ablation conditions suitable for providing appropriately sized particles for ICP-MS analysis? Experimental conditions in which a particular size is generated could lead to conditions less than ideal for ICP-MS chemical analysis. For example, changes in the sample environment such as decreasing pressure inside the ablation chamber or even the use of vacuum has been shown to decrease the particle size [17]. But these environments prevent the transport of the ablated mass out of the ablation chamber and into the ICP-MS. Therefore compromise conditions (laser, environment and detection) that allow control of the particle size, efficient transport and subsequent analysis are necessary.

The ablation "behavior" of a sample can be described by three parameters, namely: ablation rate, particle size distribution, and particle chemistry. These parameters govern the ICP-MS signal in terms of accuracy, precision and sensitivity. The importance of controlling these parameters is observed for example, when using calibration curves for quantitative analysis. In many cases a calibration curve (ICP-MS signal versus concentration) would not be an accurate representation of the analyte behavior between samples unless the ICP-MS signal was normalized to the mass, the volume of mass ablated or an internal standard of known concentration. Even if the amount of mass or volume ablated was the same for different samples, there is no guarantee that the particle size, size distribution and overall "behavior" would be the same.

There have been many studies about particle size distributions reported using nanosecond and femtosecond laser ablation [1;3;12;18-23]. However, an ideal particle 
size for LA-ICP-MS has not been established mainly due to inherent differences between instruments, experimental conditions, and samples. In many cases, as in this study, it is necessary to determine particle size and size distribution, and then examine how these particles affect the ICP-MS chemical analysis.

In the case of nanosecond laser ablation, it has been well documented [1-5] that the particle size and size distribution will strongly depend on the experimental conditions and sample properties. The primary thermal nature of nanosecond laser ablation can lead to formation of a molten layer, preferential vaporization of elements, and ejection of melted particles, in addition to particles formed from condensation. The ejection of molten mass leads to the formation of large particles $(>200 \mathrm{~nm})$ [4;24]. Large particles $(>200 \mathrm{~nm})$ that are successfully transported to the ICP may not be completely vaporized, which may result in elemental fractionation in the ICP $[5 ; 12]$. The formation of these particles is primarily determined by the laser (energy, spot size, focusing conditions, etc.); as well as surface tension and fluid stability. Femtosecond laser ablation, on the other hand, can be predominantly non-thermal; the phonon relaxation time (heating) in a solid is of the order of $\sim 100$ fs to a few ps. With femtosecond-pulsed ablation, the irradiated volume can explode (Coulomb explosion) before the photon energy is dissipated as heat in the lattice; melting is reduced (reducing or eliminating melt ejection) and the ablation process could produce a more uniform aerosol compared to nanosecond laser ablation [25]. Improved chemical analysis precision and accuracy by reducing systematic errors related to the particle size distribution and resultant spikes in the transient signal as well as a relaxation of matrix dependence has been shown for the analysis of glass and metal alloy samples when using femtosecond laser pulses [26-30]. 
The goal of this work was to characterize particles produced by UV-nanosecond and UV-femtosecond laser ablation for three series of alloy standard reference materials and pure $\mathrm{Zn}$, by measuring particle size distributions, crater volumes, crater profiles, and establishing correlations with ICP-MS performance.

A set of useful definitions for this paper is based on the morphological properties of the particles: Primary particles are defined as the smallest identifiable individual particles. Hard agglomerates are assemblies of primary particles held together by strong bonds, probably ionic/covalent in nature. Soft agglomerates are assemblies of primary particles or hard agglomerates held together by weak bonds which may be due to van der Waals forces or ionic/covalent bonds operating over very small contact areas [9;31], cf (figure 1).

\section{Experimental}

The experimental system and conditions are shown in figure 2. The experimental setup included a femtosecond laser system consisting of a Spectra Physics Mai Tai Ti:sapphire seed laser and Spitfire regenerative amplifier. The $150 \mathrm{fs}$ pulses at $800 \mathrm{~nm}$ were frequency tripled to obtain the 266-nm wavelength. The fourth harmonic of the Nd:YAG laser was used for the nanosecond (4 ns) ablation studies. An ICP-MS (VG PQ3 from VG Elemental) was used to chemically analyze the ablated mass and a DMA (Differential Mobility Analyzer) was used for the particle size measurement.

Laser ablation occurred in an argon environment under atmospheric pressure; the flow rate of the argon in the chamber was $1.25 \mathrm{~L} / \mathrm{min}$. The same laser energy and spot size was used (same fluence) for both laser systems. For the particle size distribution measurements, a flow switch was installed before the inlet to the DMA to ensure the 
working flow rate of $0.3 \mathrm{~L} / \mathrm{min}$; the rest of the flow was discarded through a filter. The differential mobility analyzer (DMA) with air under atmospheric pressure can measure particle diameter from $10 \mathrm{~nm}$ to $850 \mathrm{~nm}$. However in argon, arc discharging occurred at voltages lower than the design value in air and reduced the maximum measured particle size from $850 \mathrm{~nm}$ to $\sim 400 \mathrm{~nm}$. In addition, the measurement process requires a scanning time of at least 1 minute for each data acquisition. However, the size of laser-ablated particles may change with time as a crater is developed. Therefore, to get a uniform particle generation during the measurement, the samples were translated at a constant speed during ablation $(10 \mu \mathrm{m} / \mathrm{sec})$ to eliminate the effects of changing crater shape on particle size; this was confirmed by preliminary ICP-MS measurements that showed steady signal under these conditions. A white light interferometer microscope (Zygo-New View 200) was used for the craters profiles and volumes measurements, this instrument posses a vertical resolution of $<0.1 \mathrm{~nm}$ and a lateral resolution of 0.37 to $9.5 \mu \mathrm{m}$ objective dependent.

The samples (series of standard reference materials) used in this study were high purity zinc (99.99\%, Goodfellow), zinc alloy from the National Institute of Standard and Technology (NIST) series 625-630 (“' $\mathrm{Zn}_{95} \mathrm{Al}_{5}$ ”), zinc-aluminum alloy NIST 1736-1742 (" $\mathrm{Zn}_{99.5} \mathrm{Al}_{0.5}$ "), and aluminum alloy NIST 1710-1712 ("Al"). Tables 1-3 show the trace element concentration and matrix composition for these standards. (https://srmors.nist.gov/).

\section{Results and discussion}

\section{Particle size measurements}


Most particle size distribution functions can be described using the following parameters: number density, particle diameter and span.

Number density: when using the differential mobility analyzer (DMA) system the primary measurement is the differential number concentration $(\mathrm{dN})$ of the aerosol per unit volume of gas sampled,; which is the concentration of particles in a given channel. The DMA system is sensitive to the number of particles in the aerosol sample as opposed to particle mass, color, shape composition or other characteristics. The normalized number concentration, $\mathrm{dN} / \mathrm{d} \log \mathrm{Dp}$, is calculated by dividing $\mathrm{dN}$ by the geometric width of the size channel. This normalized concentration format allows particle size distributions to be compared regardless of the channel resolution. Span: The span illustrates the breadth of the distribution in terms of particle size. Span is calculated from:

$$
\text { Span }=\left(D_{90}-D_{10}\right) / D_{50}
$$

Here $\mathrm{D}_{10}, \mathrm{D}_{50}$, and $\mathrm{D}_{90}$ refer, respectively, to the particle diameters below which 10 , 50, and $90 \%$ of the cumulative aerosol are found. Particle diameter: the electrical mobility diameter $\left(D_{m}\right)$ is the diameter of a sphere with the same migration velocity in a constant electric field as the particle of interest (physical diameter, $D_{p}$ ). For spherical particles $D_{m}=D_{p}[32]$.

During these experiments, each sample was ablated at 6 different surface locations, which resulted in six particle size distribution measurements. The average of these six particle size measurements was calculated and is presented in figure 3. The error bars represent the standard deviation of this average.

Number density: In figure $3 a-d$, significant differences in the number density of particles was measured in the $10-400 \mathrm{~nm}$ range by using femtosecond compared to 
nanosecond laser ablation. The larger number density of particles from femtosecond laser ablation originates from a higher ablation rate (more ablated mass hence more particles). Figure 4 shows the crater profiles (samples Zn (a), NIST 627 (b), and NIST 1711 (c)) measured with a white light interferometer microscope (Zygo-New View 200). These profiles showed similar crater depths. However, mass deposit was not observed around the craters (rim) produced by femtosecond pulsed laser ablation. Therefore, the net volume, measured with white light interferometric microscope, which is the difference between the volume below and above the sample surface (represented by 0 in the $y$ scale), was higher for femtosecond laser ablation. Net volume ratio (fs/ns) for the selected samples shows that fs-laser ablation produce approximately 9 (Zn), 7 (NIST627) and 5 (NIST1711) times more ablated mass compared to nanosecond pulsed ablation (table 4). These data support that the larger number density of particles produced by femtosecond laser ablation is associated with the larger amount of mass ablated from the sample. But how much mass was removed from the sample per second and how much of the ablated mass reached the DMA in an appropriate form to be measured? .

To answer these questions comparison based on the volume of ablated material per second, calculated from the sample craters, to the number concentration of particles per second from the DMA, was made. The volume of ablated material per second from the sample craters was calculated using a prism volume equation. The prism volume equation $V=A_{\text {triangle }} h$ was used due to the triangular shape of the crater profile (figure $4 d$ ). Here $h$ is the length of the trench (ablation time $170 \mathrm{sec}$ x scan speed $10 \mu \mathrm{m} / \mathrm{sec}$ ) and $A$ is the triangle area. For these calculations only the volume of the trench removed (volume below surface, 0 in the $y$-scale) was considered. The results of these calculations as well 
as the data of number concentration of particles per second obtained from the DMA are presented in table 5. From these calculations the percentage of ablated mass per second that reaches the DMA was: pure zinc 91\% (fs) - 1.5\%(ns), NIST627 125\% (fs) - 12\%(ns) and NIST1711 $96 \%(\mathrm{fs})-15 \%(\mathrm{~ns})$. These results indicate that for fs-laser ablation, essentially all ablated mass was in suitable form to be transported to and measured by the DMA. Similar levels of transport efficiency were recently reported for NIR-fs laser ablation of brass in helium [33]. In this paper, the lower limit of transport efficiency (independent of the cell used) was reported to be about $77 \%$. This efficiency was calculated after: weighing the sample before and after ablation with a microbalance, collecting the particles by low-pressure impaction, and evaluation of the impacted masses by x-ray fluoresce spectroscopy (XRF).

To account for the missing volume, especially for nanosecond laser ablation, is not an easy task. However, it can be assumed that some of the missing volume went to the material deposited around the crater (rim or volume above the surface), and some went to large particles that were not transported to or were not measured by the DMA ( $>400 \mathrm{~nm})$.

The breadth of the distributions in terms of particle size (Span) shows no significant difference between nanosecond and femtosecond laser ablation. The calculated spans for all the samples particle size distribution functions yield an average of 1.6 for nanosecond laser ablation and 1.7 for femtosecond laser ablation.

Particle diameter: Comparison of the median particle size (median particle size represents the value in which the distribution function is split in half, $50 \%$ of the particles are above and below this value) shows that nanosecond laser ablation produced smaller particles than femtosecond laser ablation (cf. figure 3). This observation is consistent for 
all the samples within and between the different series of alloy standards and pure zinc. An apparent contradiction to the general assumption that femtosecond laser ablation generates smaller particles compared to nanosecond laser ablation is notable [28]. One explanation could be provided by evidence that nanosecond laser ablation produces a bimodal distribution in which there is a maximum at particle size range of 10-200 nm and another at larger particle sizes $(>600 \mathrm{~nm})$ [15]. Since particles size measurements, in this study, are only been carry out for particles between the range of 10-400nm (due to DMA limitations), it is plausible to assume that the majority of mass ablated by nanosecond laser pulses were particles $>600 \mathrm{~nm}$. From this point of view, femtosecond laser ablation is producing a larger number of particles in the range of $10-400 \mathrm{~nm}$, which are better suited for ICP-MS.

Another uncertainty derives from the fact that the method used for measuring the particle size distribution assumes spherical shape of the particles[32]. However, this is not always the case and deviation of the spherical shape leads to discrepancies in the size determined (over- or underestimation). For DMA measurements, the electrical mobility $Z_{p}$ is related to the size of the aerosol particles. The definition of $Z_{p}$ is $Z_{p}=\frac{n e C_{c}\left(D_{m}\right)}{3 \pi \eta D_{m}}$ where, $n$ is the number of elementary charges on a particle, $e$ is the elementary charge $\left(1.6 \times 10^{-19}\right.$ Coulomb $), C_{c}$ is the Cunningham slip correction, $\eta$ is the gas viscosity, and $D_{m}$ is the electrical mobility diameter. When particles deviate from spherical, in particular for the case of soft or hard agglomerates of particles, the drag force experienced is larger but the electrical force is the same, so it is "sized" as a mobilityequivalent sphere that is larger than its sphere physical diameter. For compact hard 
agglomeration of particles with and without internal voids, $D_{m} \approx D_{p}$, and for soft agglomeration of particles with or without internal voids $D_{m}>D_{p}$, where $D_{p}$ is the physical diameter [32]. To investigate which of the possibilities presented above is responsible for the DMA data showing that the nanosecond pulsed laser produces smaller particles than the femtosecond pulsed laser, characterization of particles by means of scanning electron microscopy (SEM) was performed.

For SEM measurements, NIST 1711 and Zn were ablated using the same conditions as above; the ablated mass was collected on small clean silicon substrates. Particles were collected at the exit of the ablation chamber after a distance of 1 meter of tubing (normal input to the ICP-MS). The particle collection time for both nanosecond and femtosecond ablation was the same (480sec).

SEM images show that the particle shapes and sizes were different for nanosecond and femtosecond laser ablation, figures 5 and 6 . Individual particles and clusters were observed with both lasers. From nanosecond laser ablation, individual particles and clusters have irregular shapes. Clusters of particles appearing to be melted together are referred to here as hard agglomeration of particles [with irregular shape as is the case of nanosecond Zn (figure 5b-c) and NIST 1711 (figure 6b-c) or with compact shape as for femtosecond $\mathrm{Zn}$ (figure 5f-g)]. From femtosecond ablation, however, most of the individual particles have spherical shape and the clusters of particles are gathering of primary particles to form soft agglomerations (except for zinc sample, where some hardagglomerates are also visible). The differences between soft and hard agglomeration of particles reside in the type of interaction between the primary particles. A soft agglomeration of particles can be separated into its primary constituents without losing 
their shape and properties, while this is not possible from a hard agglomeration of particles. Soft agglomeration of particles can be broken into primary particles and/or hard agglomerates. From these images, it is reasonable to speculate that DMA measurements are more reliable for particles generated by the femtosecond laser due to their spherical shape. Moreover, femtosecond laser ablation particles in the SEM images are in concordance with the DMA particle size distributions. However, even though for femtosecond laser ablation most of the produced particles were transported and measured by the DMA, an overestimation of the size cannot be completely ruled out, due to the appearance of soft agglomerates in these images.

Studies of particle formation by flame aerosol reactors [8-11] show that the particle size strongly depends on: the precursor concentration [affects number of collisions (atoms and clusters) at early times, which will affect the size of the primary particles]. A high maximum flame temperature accelerates reaction kinetics and prolongs particle coalescence, promoting the formation of larger primary particles. High cooling rate prevents coalescence, resulting in smaller primary particle sizes. Long residence times prolong particle coalescence, thereby increasing the primary particle size. By controlling these parameters, researchers can customize the particle size in a flame. Experimental conditions in a flame aerosol reactor may be "easier" to control than in a laser ablation experiment. Nonetheless, parameters such as the amount of ablated mass and cooling rate are expected to play similar roles in laser ablation experiments. In laser ablation, as in flame aerosol reactors, a larger amount of precursor (amount of ablated mass) will increase vapor density and number of atomic collisions at early times, thus increasing the primary particle size. However, even though the effect of cooling rate in the particle 
formation and growth is not completely understood for laser ablation, it is safe to assume that a faster plasma cooling rate will influence the volume of material melted and the production of particles from the molten layer. Femtosecond laser induced plasma temperature and electron number density decrease faster in the first $250 \mathrm{~ns}$ after the laser pulse interacts with the sample compared to nanosecond induced plasmas [34]. Even though femtosecond laser ablation generated a larger amount of ablated mass compared to nanosecond laser ablation under the conditions in this study, the contribution of particles from the melted layer by nanosecond laser ablation appears to be significant for all analyzed samples. In addition to the mentioned parameters that have an effect on the mechanisms of particle formation, it was recently reported by Koch et al [35], that when using NIR-ns-LA, predominantly larger particles were formed in the present of argon compared to helium. They attributed these observations to the increased collisions frequency between particles product of the dynamic expansion patterns. In contrast for NIR-fs-LA, these dynamic expansion patterns were chaotic and consisted in multiple branches independent of the background gas, producing smaller particles and agglomerates compared to NIR-ns-LA. A close observation of the particles in figures 5 and 6 shows, that in addition to large agglomeration of particles some individual particles were as large as micrometers in size, suggesting that they have been ejected from the melted surface instead of being condensed from the ablated plasma vapor.

The sizes of particles (primary and hard agglomerates) from nanosecond ablation ranged widely from several tens to thousands of nanometers. The large particles (primary and soft agglomerates) from femtosecond ablation have a different structure. They were neck-shaped (Zn) or perfectly spherical particles (NIST 1711) and soft agglomerates 
formed from several small particles. These small particles seem ranged from 10 to 50 nanometers (unresolved particles on the SEM images $6 g$-h), which are positioned next to each other reaching dimensions of several micrometers. There were fewer single large droplets compared to those observed with nanosecond ablation, suggesting that melting and ejection of molten mass was less prominent. This data confirmed that nanosecond pulsed ablation produces larger particles compared to femtosecond pulsed laser ablation as was also showed by Koch et al [35] for NIR-ns and NIR-fs-LA.

The different particle shapes and sizes between the studied samples cannot directly be explained by chemical composition, due to the complexity of some of the samples. However, a trend was observed when plotting the number concentration, $\mathrm{dN} / \mathrm{d} \log \mathrm{Dp}$ (normalized to the maximum value) for: $\boldsymbol{a}$ ) nanosecond and $\boldsymbol{b}$ ) femtosecond (figure 7) and the median particle size versus the aluminum concentration (figure 8). For nanosecond laser ablation (figure 7a) the particle size distribution modes (which represent the maxima of the distribution functions) are shifted with respect to each other when compared between the standard series. It is also noticeable that the error bars (representing standard deviation between particle size distributions) in each distribution for nanosecond laser ablation are larger than those from femtosecond laser ablation. The modes shift from $40 \mathrm{~nm}$ for NIST $1736-1742$ to $65 \mathrm{~nm}$ for NIST $625-630$ and $80 \mathrm{~nm}$ for NIST 1710-1712. In contrast, for femtosecond laser ablation the mode is $90 \mathrm{~nm}$ for NIST 1736-1742, $110 \mathrm{~nm}$ for NIST $625-630$, and $140 \mathrm{~nm}$ for NIST $1710-1711$. The total size variation measured with the nanosecond laser is a range of about $2: 1$, whereas the same ratio for femtosecond laser ablation is about 1.5:1. 
An increase in the median particle size was observed with increased aluminum concentration (figure 8). Based only on the $\mathrm{Zn}$ and $\mathrm{Al}$ properties, it is possible to speculate that, as the plasma and surroundings cool down [assuming the same starting plasma and surrounding temperatures, above the sample boiling point] the ablated mass with higher boiling point will condense and resolidify sooner than the ablated mass with lower boiling point. The ablated mass that condenses first will have a higher probability to coalesce, due to the longer time in the liquid phase. The boiling and melting temperatures of zinc (1180 and $693 \mathrm{~K}$, respectively) are lower than aluminum (2792 and $993 \mathrm{~K}$ ); coalescence could be more important in aluminum ablation. From this analysis it is expected that samples with higher aluminum concentration would present the largest particles, which seems to be the case from the SEM images and DMA measurements. A concentration of $5 \% \mathrm{Al}$ in the $\mathrm{Zn}$ alloy increases the particle size by about $65 \%$ for nanosecond laser ablation. A similar but less dramatic effect $(\sim 30 \%)$ was observed with femtosecond pulses. We speculate that small concentrations of $\mathrm{Al}$ in $\mathrm{Zn}$ may accelerate nucleation of liquid droplets in the supercooled vapor phase.

The effects of these particles on the ICP-MS performance also were studied. The ICP-MS transient signals were consistently greater for femtosecond compared to nanosecond laser ablation (figures 10). The ratio of the integrated signals (fs/ns) and temporal relative standard deviation (\%TRSD, as a measurement of the signal stability) were used as a basis of comparison between femtosecond and nanosecond laser ablation. For ${ }^{66} \mathrm{Zn}$ in pure zinc the ratio of the integrated signals (fs/ns) was 50, with TRSD of $17 \%$ ns and $2 \%$ fs, for ${ }^{66} \mathrm{Zn}$ in NIST 627 the ratio of the integrated signals was 23 with TRSD of $20 \% \mathrm{~ns}$ and $2 \% \mathrm{fs}$, and 12 times for ${ }^{27} \mathrm{Al}$ in NIST 1711 with TRSD of $23 \%$ ns and $3 \%$ 
fs. As showed earlier, the total size variation measured with the nanosecond laser is a range of about 2:1, whereas the same ratio for femtosecond laser ablation is about 1.5:1. And even though, these ratios do not appear to be that remarkably different, when introducing these aerosols into the ICP-MS these small differences become significant when comparing ns to fs-LA.

A clear trend indicating advantages of femtosecond over nanosecond laser ablation for the ablation of metallic samples was observed for all measurements performed in this study; the net ablated volume from the crater profile measurements indicates that more mass was removed from the sample with femtosecond laser pulses with less thermal damage (heat affected zone and rim formation). The total concentration of particles normalized by volume demonstrates that a greater number of particles with suitable sizes to be transported and measured by the DMA was produced by femtosecond laser ablation (table 5), and the ratio of the ICP-MS integrated signal demonstrated that more mass from femtosecond laser ablation reached and was digested by the ICP compared to nanosecond laser ablation (table 4). The ratio of the integrated signal to volume net (table 4) could be used as a measure of the overall improved efficiency by femtosecond compared to nanosecond laser ablation; for these samples it was shown that there is an improvement of 10, 2.5, and 1.7 times for Zn, NIST 627, and NIST 1711, respectively.

The discussion in this study is focused specifically on metallic samples and the results cannot be generalized to other materials even using the same laser conditions. In general, significant differences in material properties such as the absorption coefficient, thermal diffusivity, etc. could generate completely different ablation behavior. A study of 
glass samples under the same condition used in this paper is presented in a follow-up paper.

\section{Summary}

Metal particles produced by nanosecond and femtosecond laser ablation at a fluence of $50 \mathrm{~J} \mathrm{~cm}^{-2}$ in argon were different in size and morphology. Particles produced by nanosecond laser ablation mainly consisted of primary particles with irregular shape and hard agglomerates (without internal voids). Particles produced by femtosecond laser ablation consisted of spherical primary particles and soft agglomerates formed from numerous small particles. There were fewer single large droplets formed by femtosecond laser ablation compared with those observed with nanosecond ablation. Melting and ejection of molten mass was less prominent with femtosecond ablation.

Crater net volume showed that a larger amount of mass from the metallic samples was ablated using femtosecond laser compared to nanosecond laser ablation. Furthermore, comparison between the calculated volume from the crater and total particle concentration normalized by volume from the DMA demonstrated that most of the ablated mass using femtosecond laser ablation reached the DMA while there was a large amount of mass unaccounted for from the nanosecond craters.

The larger amount of mass ablated from the samples with the femtosecond laser pulses from these metallic samples, as in a flame aerosol reactor (with high precursor concentration), could increase the number of atomic collisions at early times, promoting the increase of the primary particle size. However, the contribution of large particles from melted layer ejection becomes an important factor in the overall aerosol quality when using nanosecond laser ablation (as observed in the SEM images) causing more mass to 
deposit around the craters, reduction in transport efficiency, reduction in ICP-MS signal, and increasing signal fluctuations (\%TRSD).

\section{Acknowledgement}

We would like to thank Sotiris E. Pratsinis, for his helpful advice on aerosol particle formation; and Paul Berdahl for productive discussions and for editing the manuscript. This work was supported by the Office of Science, Office of Basic Energy Sciences, Chemical Sciences, Geosciences, and Biosciences Division, and the Deputy Administrator for Defense Nuclear Nonproliferation, Research and Development of the U.S. Department of Energy under Contract No. DE-AC02-05CH11231.

\section{List of tables}

Table 1: Compositions of the reference standard series NIST 625-630

Table 2: Compositions of the reference standard series NIST 1710-1712

Table 3: Compositions of the reference standard series NIST 1736-1742

Table 4: Volumes calculated from crater geometric shape and from DMA measurements

Table 5: Femtosecond to nanosecond ratios; volume net $\left(\mu \mathrm{m}^{3}\right)$, total concentration $\left(\# / \mathrm{cm}^{3}\right)$ and ICP-MS integrated signal intensities.

\section{List of Figures}

Figure 1: Schematic representation of particle generation mechanisms

Figure 2: Experimental setup and conditions

Figure 3: Particle size distribution (DMA) for samples a)Zn; b)NIST $625, c$ )NIST 1737, d) NIST 1710 . 
Figure 4: White light interferometer microscope measurements of the crater profile a) Zn, b) NIST627, and c) NIST1711. d) Triangle shape used for volume calculations.

Figure 5: SEM images of Zn particles; a-d) nanosecond $\mathbf{e - h}$ ) femtosecond laser ablation.

Figure 6: SEM images of NIST 1711 particles; a-d) nanosecond e-h) femtosecond laser ablation.

Figure 7: Normalized particle size distribution (DMA) for the series NIST 1736-1742, NIST 625-630 and NIST 1710-1712. a) Nanosecond laser ablation and b) femtosecond laser ablation

Figure 8: Median particle size versus aluminum concentration (\%).

Figure 9: Particle size distribution (DMA) for the samples NIST 628 and NIST 1739 produced by a) nanosecond laser ablation, b) femtosecond laser ablation and c) ${ }^{208} \mathrm{~Pb}$ calibration curves from the two series of standards

Figure 10: ${ }^{66} \mathrm{Zn}$ transient signals produced by $10 \mu \mathrm{m} / \mathrm{sec}$ ablation (nanosecond and femtosecond) a) pure Zn and b) NIST 627

\section{Reference List}

[1] Kosler J., Wiedenbeck M., Wirth R., Hovorka J., Sylvester P., and Mikova J., J.Anal.Atom.Spectrom. 20 (2005) 402-409.

[2] Kuhn H-R and Gunther D., Analytical and Bionalytical Chemistry On line paper (2005). 
[3] Koch J., von Bohlen A., Hergenroder R., and Niemax K., Journal of Analytical Atomic Spectrometry 19 (2004) 267-272.

[4] Russo R.E., Mao X.L, Liu C.Y, and Gonzalez J., J.Anal.Atom.Spectrom. 19 (2004) 1084-1089.

[5] D.B.Aeschliman, S.J.Bajic, D.P.Baldwin, and R.S.Houk, Journal of Analytical Atomic Spectrometry 18 (2003) 1008-1014.

[6] Hergenroder R., Spectrochim.Acta Part B 61 (2006) 284-300.

[7] A.Bogaerts, Z.Y.Chen, R.Gijbels, and A.Vertes, Spectrochimica Acta Part BAtomic Spectroscopy 58 (2003) 1867-1893.

[8] Tani T., Takatori K., and Pratsinis S.E., Journal of the american ceramic society 87 (2004) 365-370.

[9] Tsantilis S. and Pratsinis S.E., Langmuir 20 (2004) 5933-5939.

[10] S.E.Pratsinis and S.Vemury, Powder technology 88 (1996) 267-273.

[11] S.E.Pratsinis, Progress in Energy and Combustion Science 24 (1998) 197-219.

[12] Kuhn H.R., Guillong M., and Gunther D., Analytical and Bioanalytical Chemistry 378 (2004) 1069-1074.

[13] Jaworski R., E.Hoffmann, and Stephanowitz H., International Journal of Mass Spectrometry 219 (2002) 373-379.

[14] Liu C. A study of particle generation during laser ablation with applications. 2005.

Ref Type: Thesis/Dissertation

[15] Kuhn H-R, Koch J., Hergenroder R., Niemax K., Kalberer M., and Gunther D., Journal of Analytical Atomic Spectrometry 20 (2005) 894-900. 
[16] Ullmann M., Friedlander S.K., and Schmidt-Ott A., Journal of Nanoparticle Research 4 (2002) 499-509.

[17] Z.Pászti, Z.E.Horváth, G.Peto, A.Karacs, and L.Guczi, Appl.Surf.Sci. 109/110 (1997) 67-73.

[18] Heitz J. and Dickinson J.T., Applied Physics A 68 (1999) 515-523.

[19] Kuhn H.R. and Gunther D., J.Anal.Atom.Spectrom. 19 (2004) 1158-1164.

[20] Liu C., Mao X.L, Gonzalez J., and Russo R.E., J.Anal.Atom.Spectrom. 20 (2005) 200-203.

[21] Koch J., Lindner H., von Bohlen A., Hergenroder R., and Niemax K., Journal of Analytical Atomic Spectrometry 20 (2005) 901-906.

[22] Weis P., Beck H.P., and Gunther D., Anal Bional Chem 381 (2005) 212-224.

[23] Koch J., Walle M., Pisonero J., and Gunther D., Journal of Analytical Atomic Spectrometry 21 (2007) 932-940.

[24] J.H.Yoo, S.H.Jeong, X.L.Mao, R.Greif, and R.E.Russo, Applied Physics Letters $76(2000) 783-785$.

[25] Gonzalez J., Mao X.L, Mao S., and Russo R.E., Journal of Analytical Atomic Spectrometry 17 (2002) 1072-1075.

[26] Gonzalez J., Dundas S.H., Liu C., Mao X.L, and Russo R.E., Journal of Analytical Atomic Spectrometry 21 (2005) 778-784.

[27] Gonzalez J., Liu C.Y, Mao X.L, and Russo R.E., Journal of Analytical Atomic Spectrometry 19 (2004) 1165-1168.

[28] C.Liu, X.L.Mao, S.S.Mao, X.Zeng, R.Greif, and R.E.Russo, Analytical Chemistry 76 (2004) 379-383. 
[29] Bian Q.Z., Koch J., Lindner H., Berndt H., Hergenroder R., and Niemax K., Journal of Analytical Atomic Spectrometry 20 (2005) 736-740.

[30] Bian Q.Z., Garcia C.C., Koch J., and Niemax K., Journal of Analytical Atomic Spectrometry 21 (2006) 187-191.

[31] Bandyopadhyaya R., Lall A.A., and Friedlander S.K., Powder technology 139 (2004) 193-199.

[32] De Carlo P.F., Slowik J.G., Worsnop D.R., Davidovits P., and Jimenez J.L., Aerosol Science and Technology 38 (2004) 1185-1205.

[33] Garcia C.C., Lindner H., and Niemax K., Spectrochimica Acta Part B-Atomic Spectroscopy 62 (2007) 13-19.

[34] Zeng X., Mao X.L, Greif R., and Russo R.E., Applied Physics A: Materials science and processing 80 (2004) 237-241.

[35] Koch J., Schlamp S., Rosgen T., Fliegel D., and Gunther D., Spectrochimica Acta Part B-Atomic Spectroscopy 62 (2007) 20-29. 


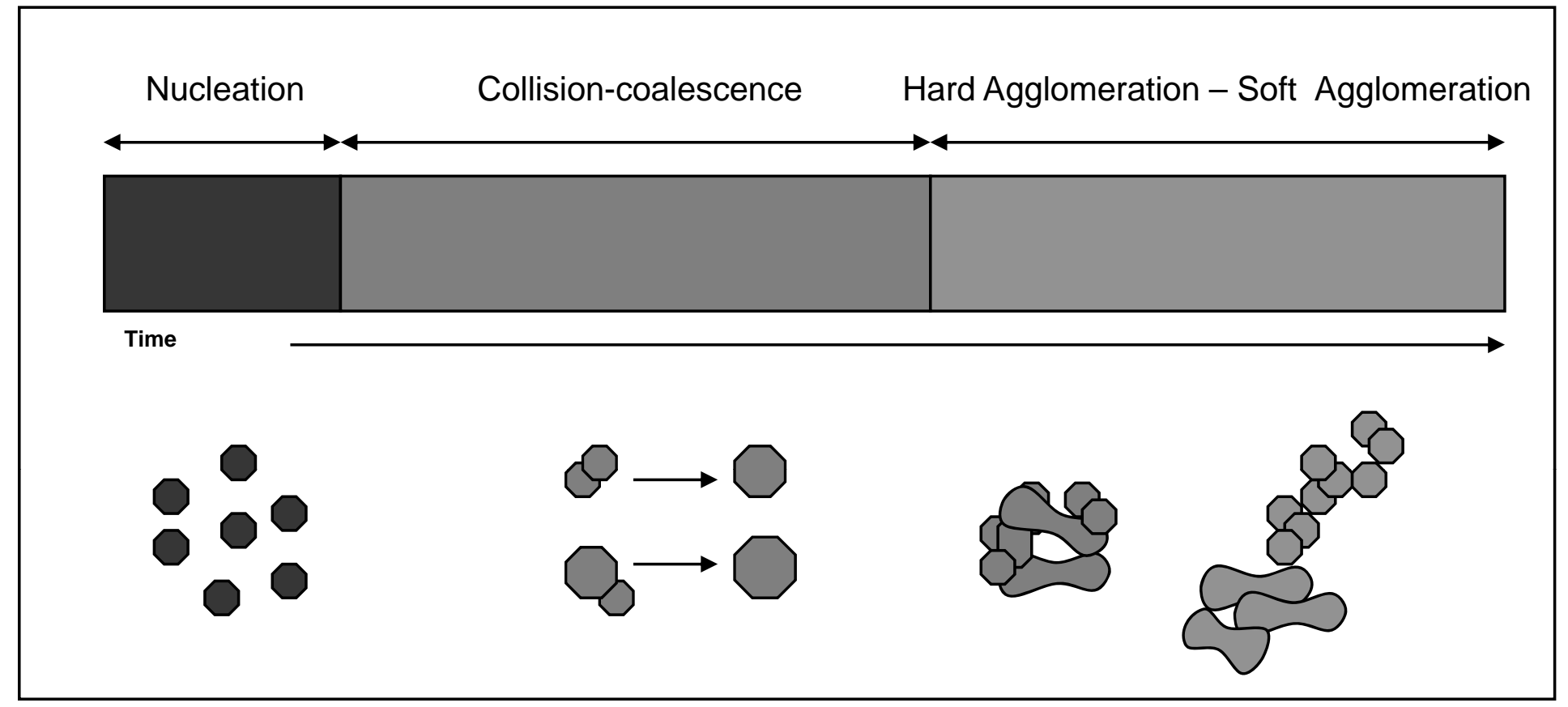

Figure 1 
Table \# 1: Elemental Composition (mass fraction, in \%)( $\left.\mathrm{Zn}_{95} \mathrm{Al}_{5}\right)$. https:/lsrmors.nist.govl

\begin{tabular}{|c|c|c|c|c|c|c|c|c|c|c|c|c|c|}
\hline SRM & SRM & $\mathrm{Cu}$ & $\mathrm{Al}$ & $\mathrm{Mg}$ & $\mathrm{Fe}$ & $\mathrm{Pb}$ & $\mathrm{Cd}$ & Sn & $\mathrm{Cr}$ & $\mathrm{Mn}$ & $\mathrm{Ni}$ & Si & $-\mathbf{Z n}$ \\
\hline 625 & Zinc -base & 0.034 & 3.06 & 0.07 & 0.036 & 0.0014 & 7E-04 & 0.0006 & 0.0128 & 0.031 & 0.0184 & 0.017 & 96.7181 \\
\hline 626 & Zinc -base & 0.056 & 3.56 & 0.02 & 0.103 & 0.0022 & 0.002 & 0.0012 & 0.0395 & 0.048 & 0.047 & 0.042 & 96.0795 \\
\hline 627 & Zinc -base & 0.132 & 3.88 & 0.03 & 0.023 & 0.0082 & 0.005 & 0.0042 & 0.0038 & 0.014 & 0.0029 & 0.021 & 95.8758 \\
\hline 629 & Zinc -base & 1.5 & 5.15 & 0.094 & 0.017 & 0.0135 & 0.016 & 0.012 & 0.0008 & 0.0017 & 0.0075 & 0.078 & 93.1100 \\
\hline 630 & Zinc -base & 0.976 & 4.3 & 0.03 & 0.023 & 0.0083 & 0.005 & 0.004 & 0.0031 & 0.0106 & 0.0027 & 0.022 & 94.6155 \\
\hline
\end{tabular}

Table \# 2: Elemental Composition (mass fraction, in \%) (AI) https:/lsrmors.nist.govl

\begin{tabular}{|c|c|c|c|c|}
\hline SRM & SRM & Cd & Pb & $\sim$ Al \\
\hline $\mathbf{1 7 1 0}$ & Aluminum Base & 0.0008 & 0.00177 & 99.9974 \\
\hline $\mathbf{1 7 1 1}$ & Aluminum Base & 0.0021 & 0.00639 & 99.9915 \\
\hline $\mathbf{1 7 1 2}$ & Aluminum Base & 0.0052 & 0.01559 & 99.9792 \\
\hline
\end{tabular}

Table \# 3: Elemental Composition (mass fraction, in \%)( $\left(\mathrm{Zn}_{99} \mathrm{Al}_{0.5}\right)$. https:/lsrmors.nist.govl

\begin{tabular}{|c|c|c|c|c|}
\hline SRM & SRM & Al & Pb & $\sim$ Zn \\
\hline $\mathbf{1 7 3 6}$ & Zinc-base & 0.3076 & 0.0029 & 99.6895 \\
\hline $\mathbf{1 7 3 7}$ & Zinc-base & 0.6302 & 0.0029 & 99.3669 \\
\hline $\mathbf{1 7 3 8}$ & Zinc-base & 0.1014 & 0.0101 & 99.8885 \\
\hline $\mathbf{1 7 3 9}$ & Zinc-base & 0.2049 & 0.0302 & 99.7649 \\
\hline $\mathbf{1 7 4 0}$ & Zinc-base & 0.4177 & 0.0691 & 99.5132 \\
\hline $\mathbf{1 7 4 1}$ & Zinc-base & 0.5242 & 0.1571 & 99.3187 \\
\hline $\mathbf{1 7 4 2}$ & Zinc-base & 0.7917 & 0.0081 & 99.2002 \\
\hline
\end{tabular}

Table 1-3 
Table 4

\begin{tabular}{|c|c|c|c|}
\hline Sample & $\mathrm{Zn}$ & NIST 627 & NIST 1711 \\
\hline Volume net ratio (fs/ns) & 5 & 9 & 7 \\
\hline Total concentrantion $(\mu \mathrm{m} 3 / \mathrm{cm} 3)$ ratio $(\mathrm{fs} / \mathrm{ns})$ & 62 & 10 & 5 \\
\hline Integrated signal intensity ratio (fs/ns) & 50 & 23 & 12 \\
\hline
\end{tabular}

Table 5

\begin{tabular}{|c|c|c|c|c|c|c|c|c|c|c|c|c|c|c|c|}
\hline & \multirow{2}{*}{\begin{tabular}{|c|} 
From crater \\
$\begin{array}{c}\text { Scan speed } \\
\mu \mathrm{m} / \mathrm{sec}\end{array}$ \\
\end{tabular}} & & & & & & & & & \multicolumn{5}{|c|}{ From DMA } \\
\hline & & & $\begin{array}{l}\text { Time } \\
\text { (sec) }\end{array}$ & $\begin{array}{c}\text { Distance } \\
(\mu \mathrm{m})\end{array}$ & $\begin{array}{l}\text { Base } \\
(\mu \mathrm{m})\end{array}$ & $\begin{array}{l}\text { High } \\
(\mu \mathrm{m})\end{array}$ & $\begin{array}{c}\text { Area } \\
(\mu \mathrm{m} 2)\end{array}$ & $\begin{array}{c}\text { Volume } \\
(\mu \mathrm{m} 3)\end{array}$ & \multicolumn{2}{|l|}{$\begin{array}{c}\text { Volume/sec } \\
(\mu \mathrm{m} 3 / \mathrm{sec})\end{array}$} & $\mathrm{nm} 3 / \mathrm{cm} 3$ & $\mu \mathrm{m} 3 / \mathrm{cm} 3$ & $\begin{array}{l}\text { Flowrate } \\
\text { (cm3/sec) }\end{array}$ & $\begin{array}{c}\text { Volume/sec } \\
(\mu \mathrm{m} 3 / \mathrm{sec})\end{array}$ & $\begin{array}{c}\text { Volume } \\
\text { fs/ns }\end{array}$ \\
\hline \multirow[t]{2}{*}{$\mathrm{Zn}$} & ns & 10 & 170 & 1700 & 20 & 20 & 200 & 340000 & 2000 & ns & $5.86 \mathrm{E}+09$ & 5.86 & 5 & 29.3 & 62 \\
\hline & fs & 10 & 170 & 1700 & 20 & 20 & 200 & 340000 & 2000 & fs & $3.64 \mathrm{E}+11$ & 364 & 5 & 1820 & \\
\hline \multirow[t]{2}{*}{ N627 } & ns & 10 & 170 & 1700 & 20 & 20 & 200 & 340000 & 2000 & ns & $4.91 \mathrm{E}+10$ & 49.1 & 5 & 245.5 & 10 \\
\hline & fs & 10 & 170 & 1700 & 20 & 20 & 200 & 340000 & 2000 & $\mathrm{fs}$ & $5.02 \mathrm{E}+11$ & 502 & 5 & 2510 & \\
\hline \multirow[t]{2}{*}{ N1711 } & ns & 10 & 170 & 1700 & 13 & 25 & 162.5 & 276250 & 1625 & ns & $5.87 \mathrm{E}+10$ & 58.7 & 5 & 293.5 & 5 \\
\hline & fs & 10 & 170 & 1700 & 13 & 22 & 143 & 243100 & 1430 & fs & $2.77 \mathrm{E}+11$ & 277 & 5 & 1385 & \\
\hline
\end{tabular}




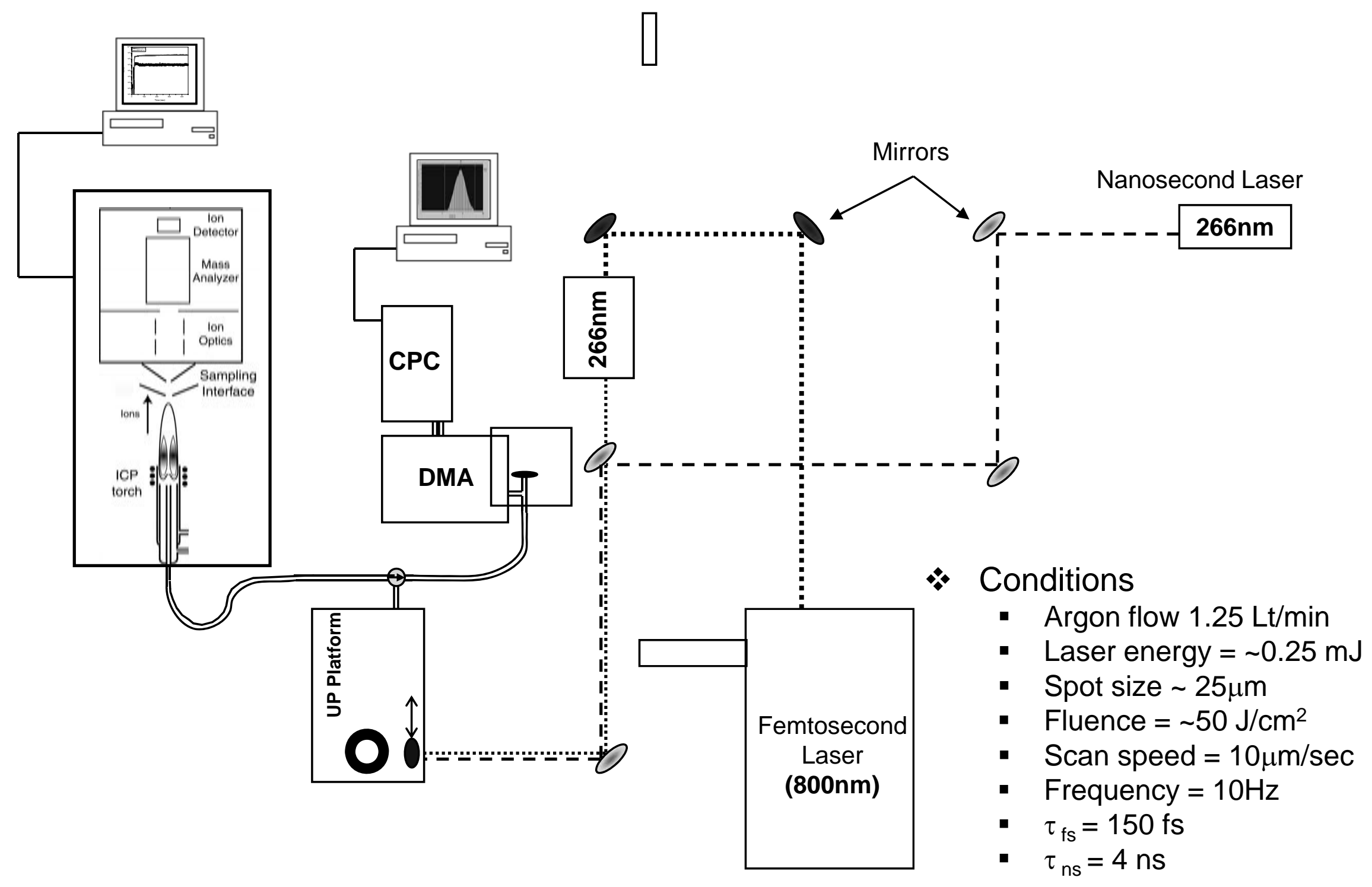

Figure 2 

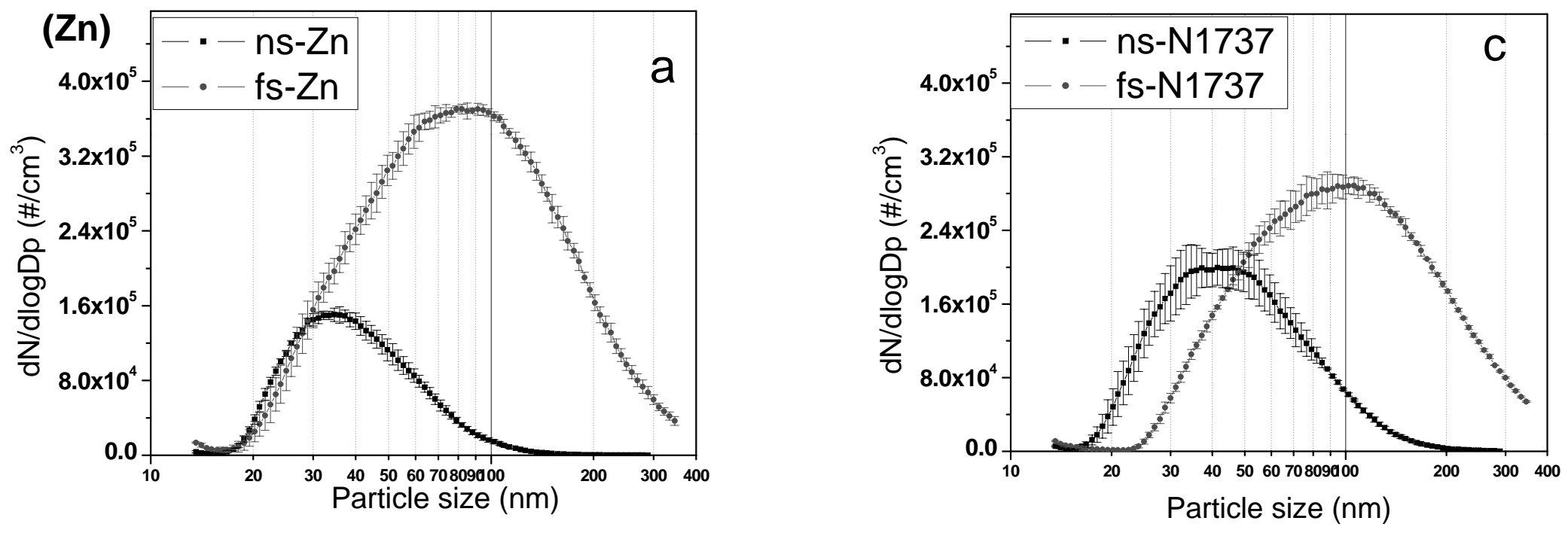

$\left(\mathrm{Zn}_{99} \mathrm{Al}_{0.5}\right)$
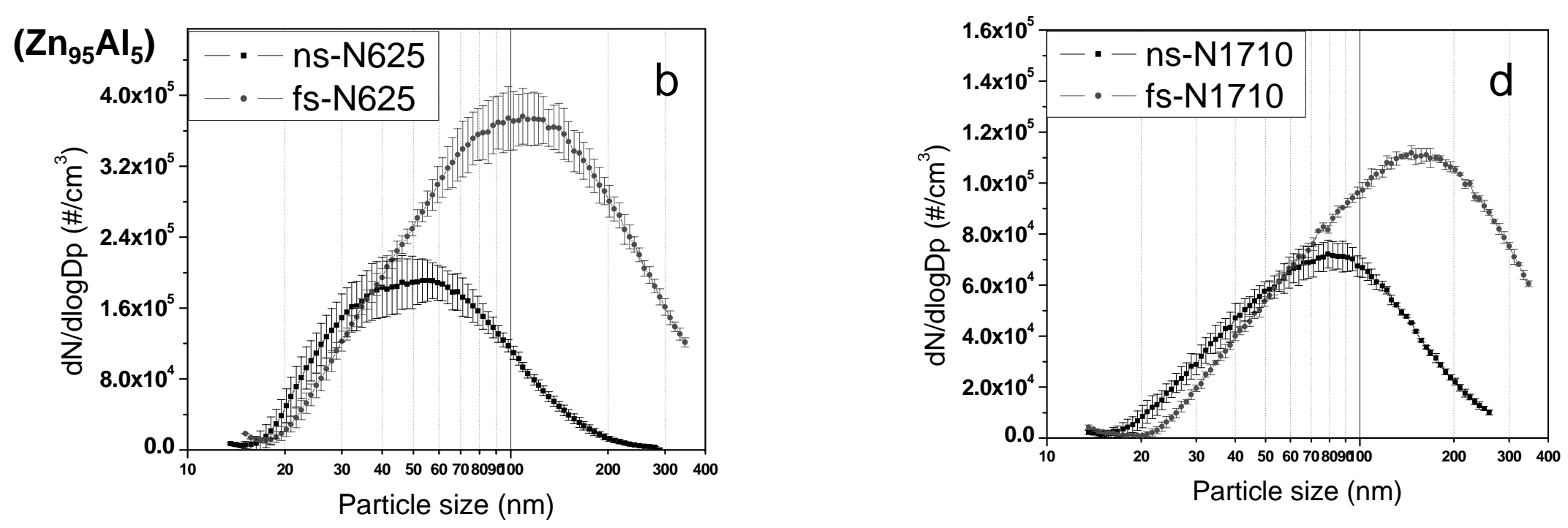

Figure 3 
Craters profile $10 \mu \mathrm{m} / \mathrm{sec}$
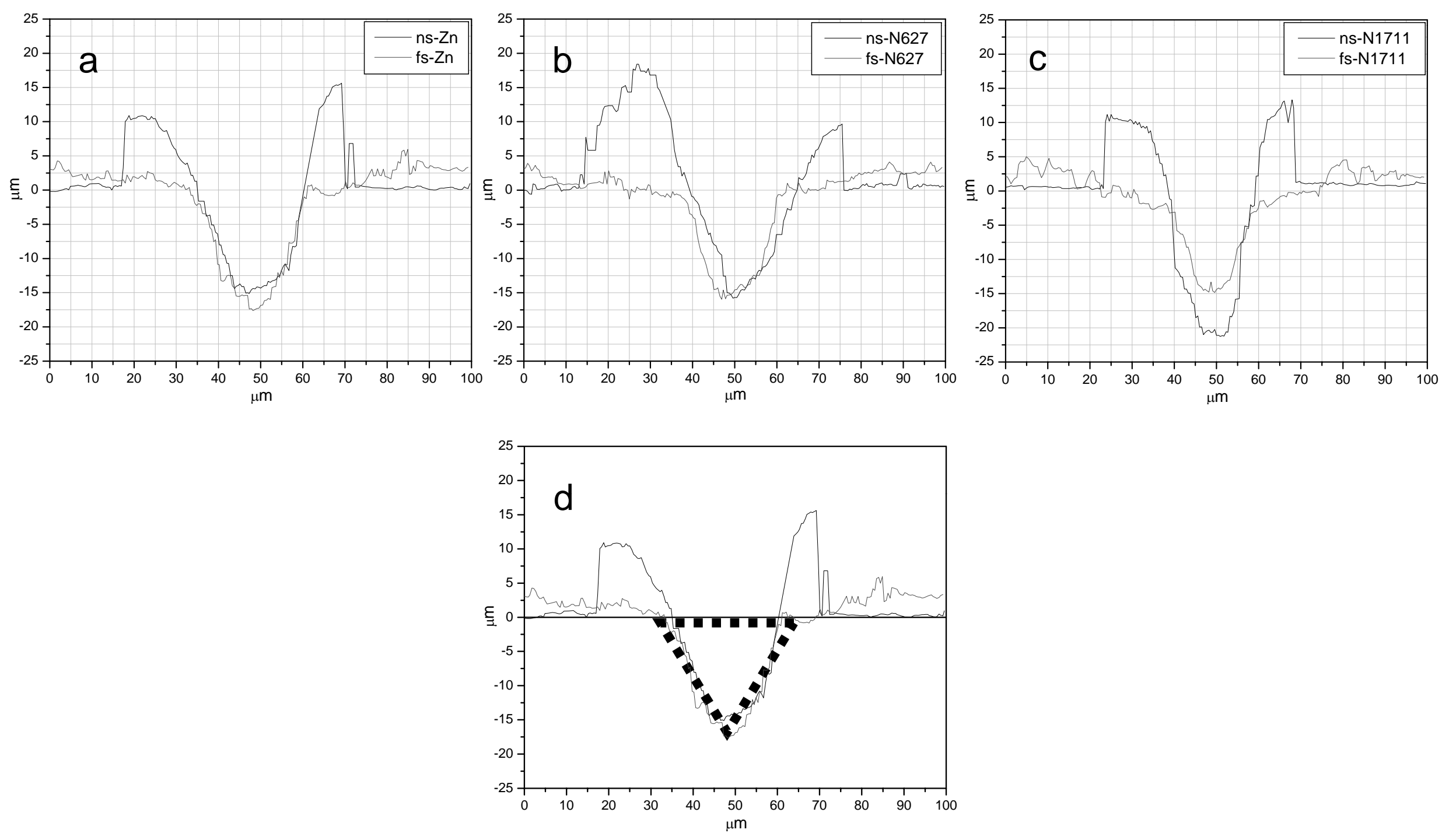

Figure 4 


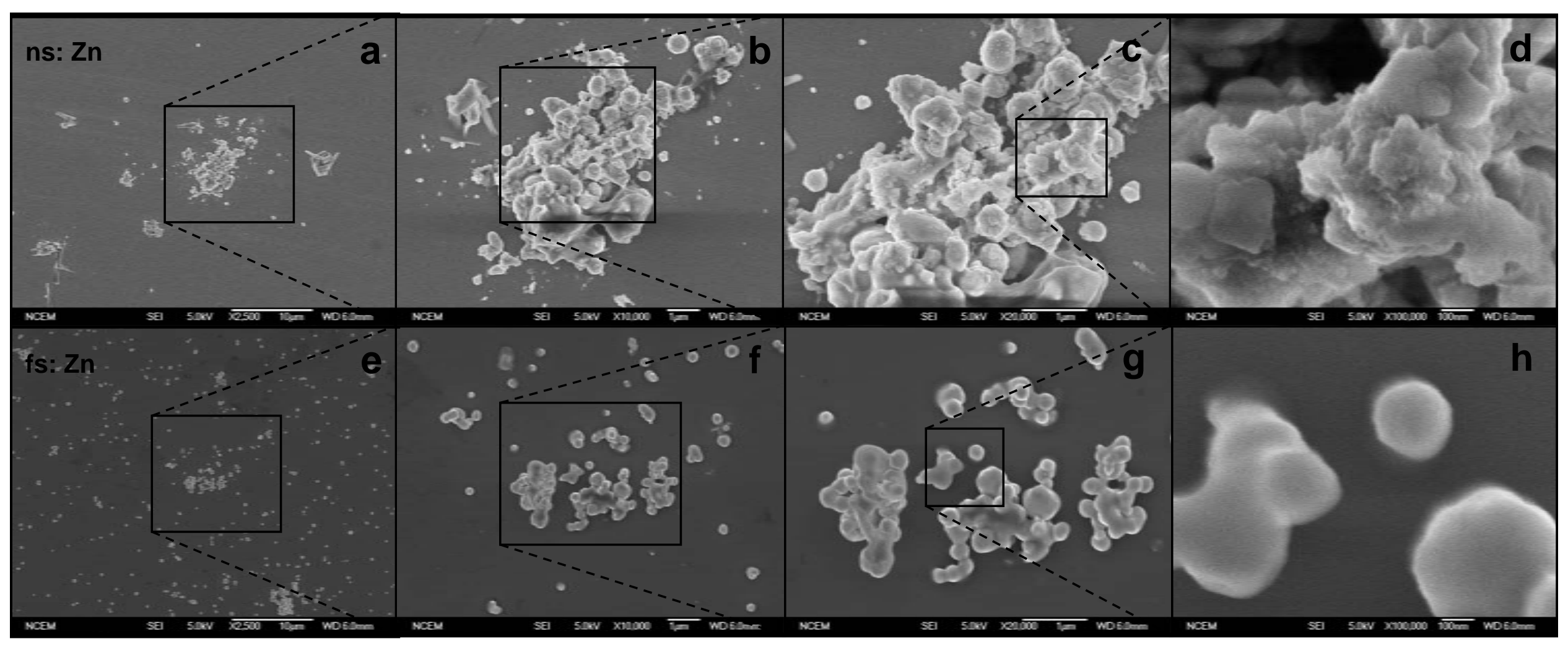

Figure 5 


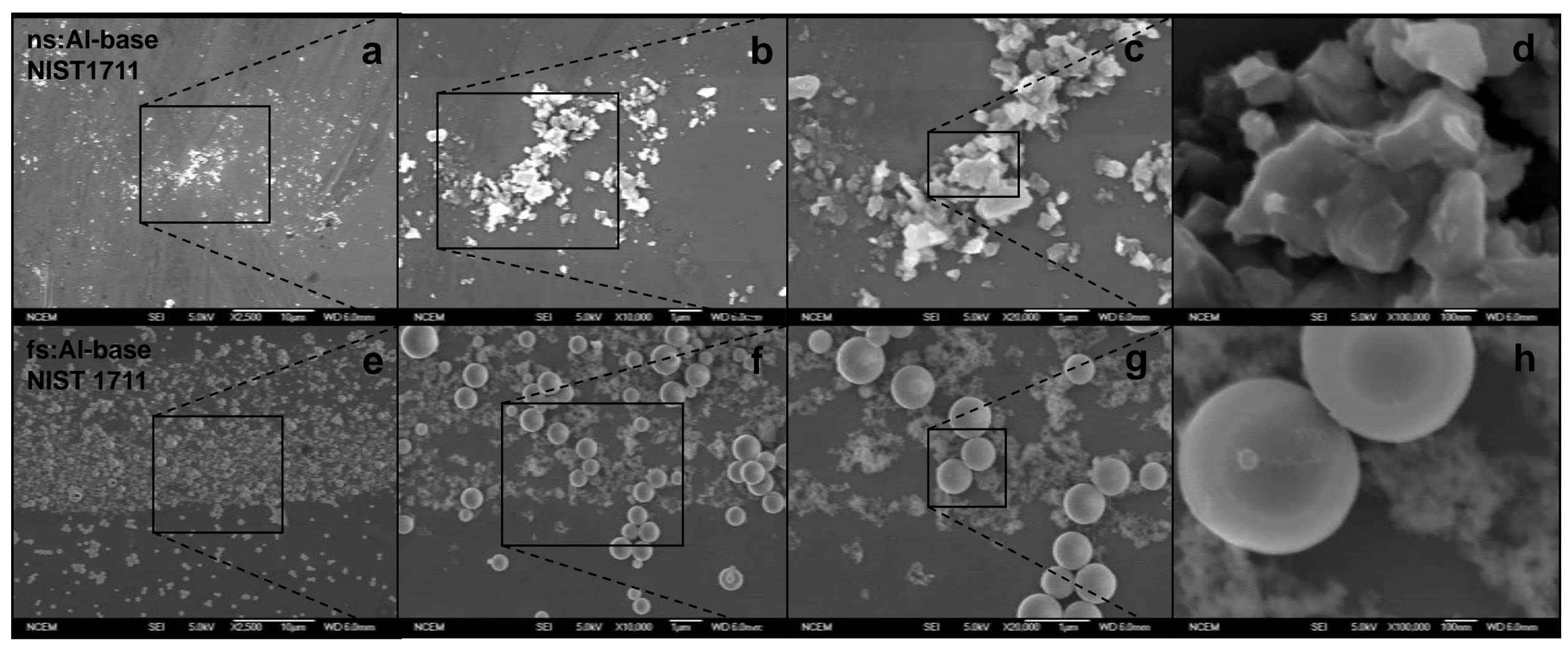

Figure 6 
NIST Series 1736-1742, 625-630 and 1710-1712

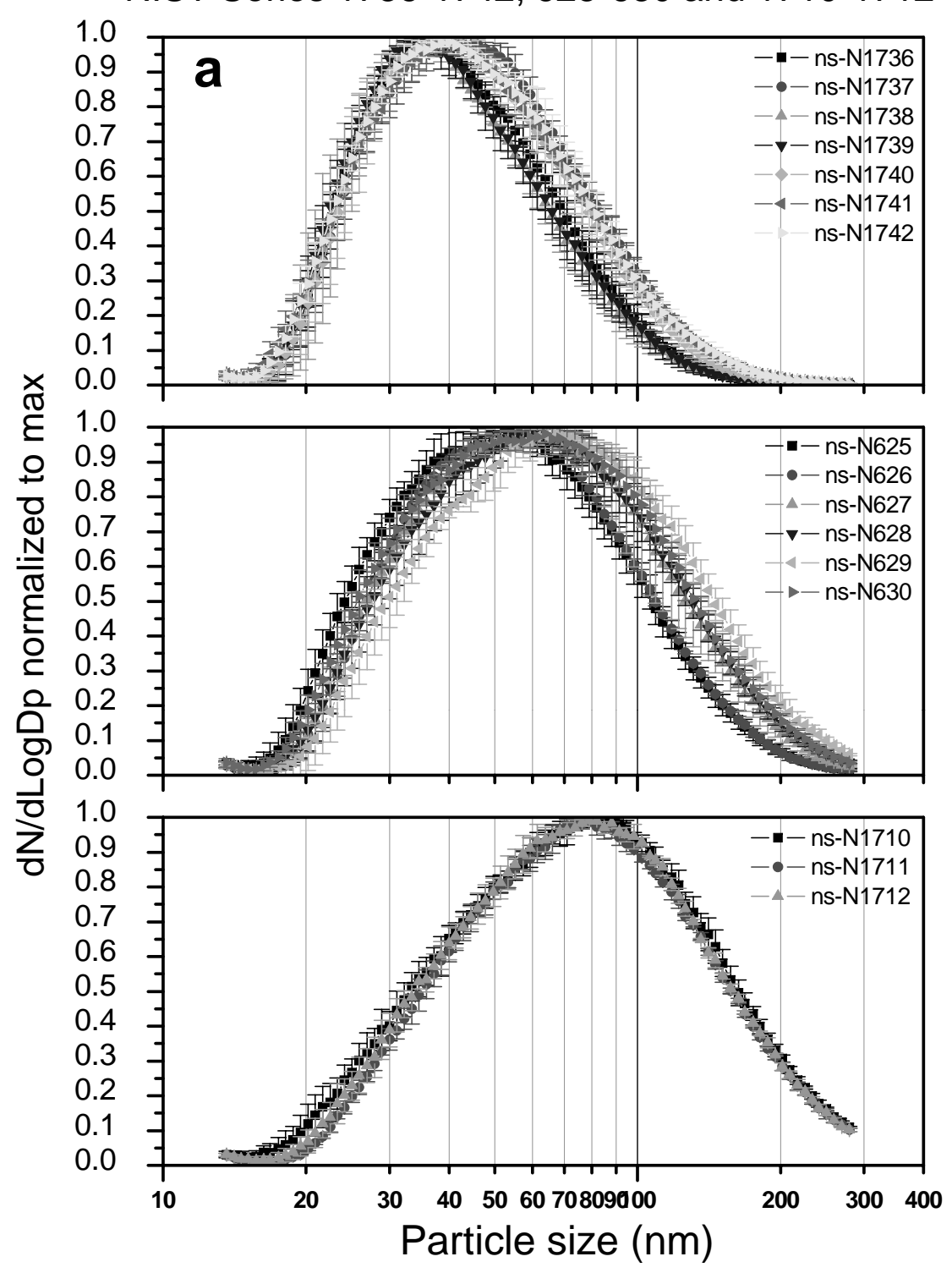

NIST Series 1736-1742, 625-630 and 1710-1712

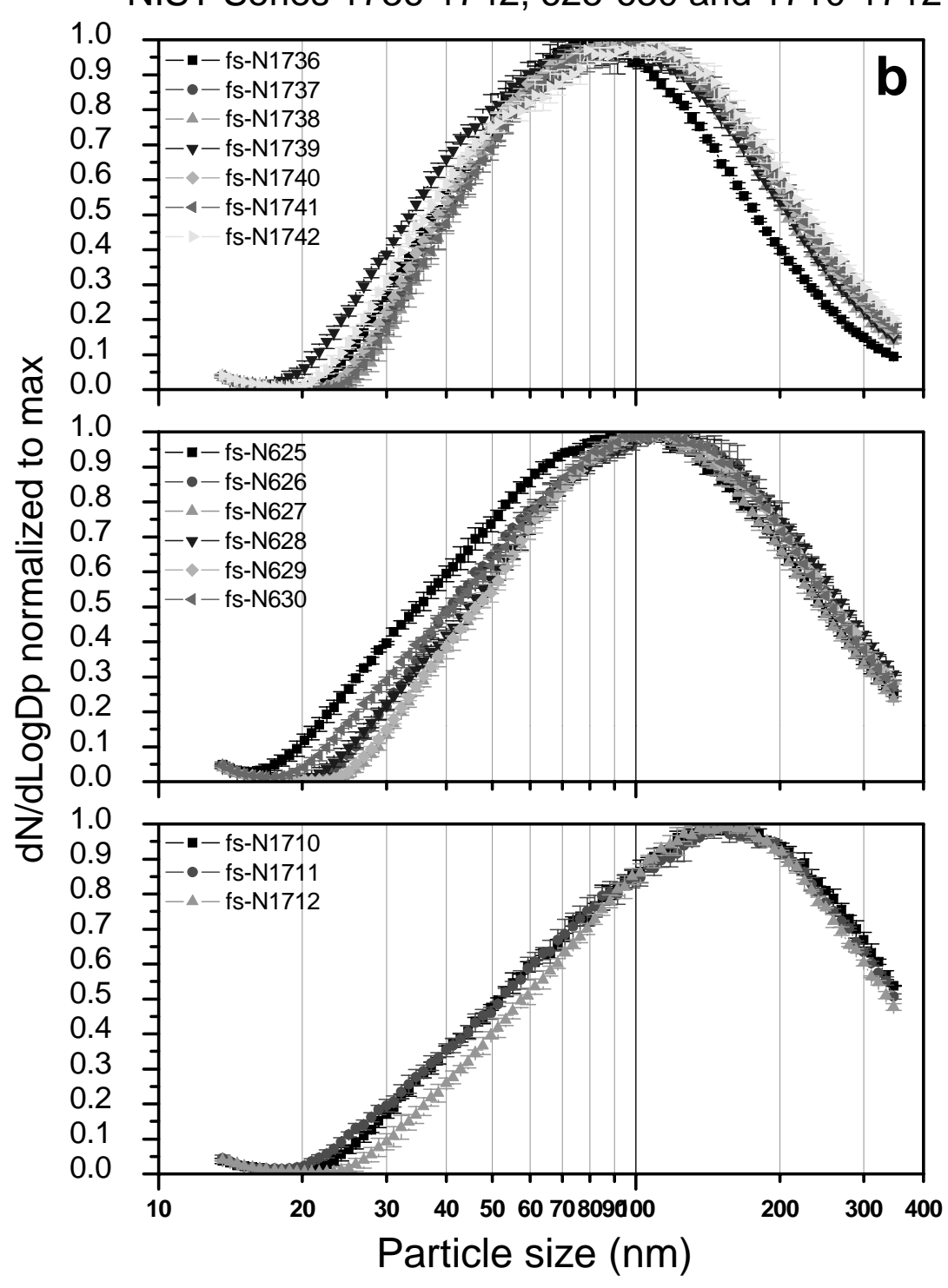

Figure 7 


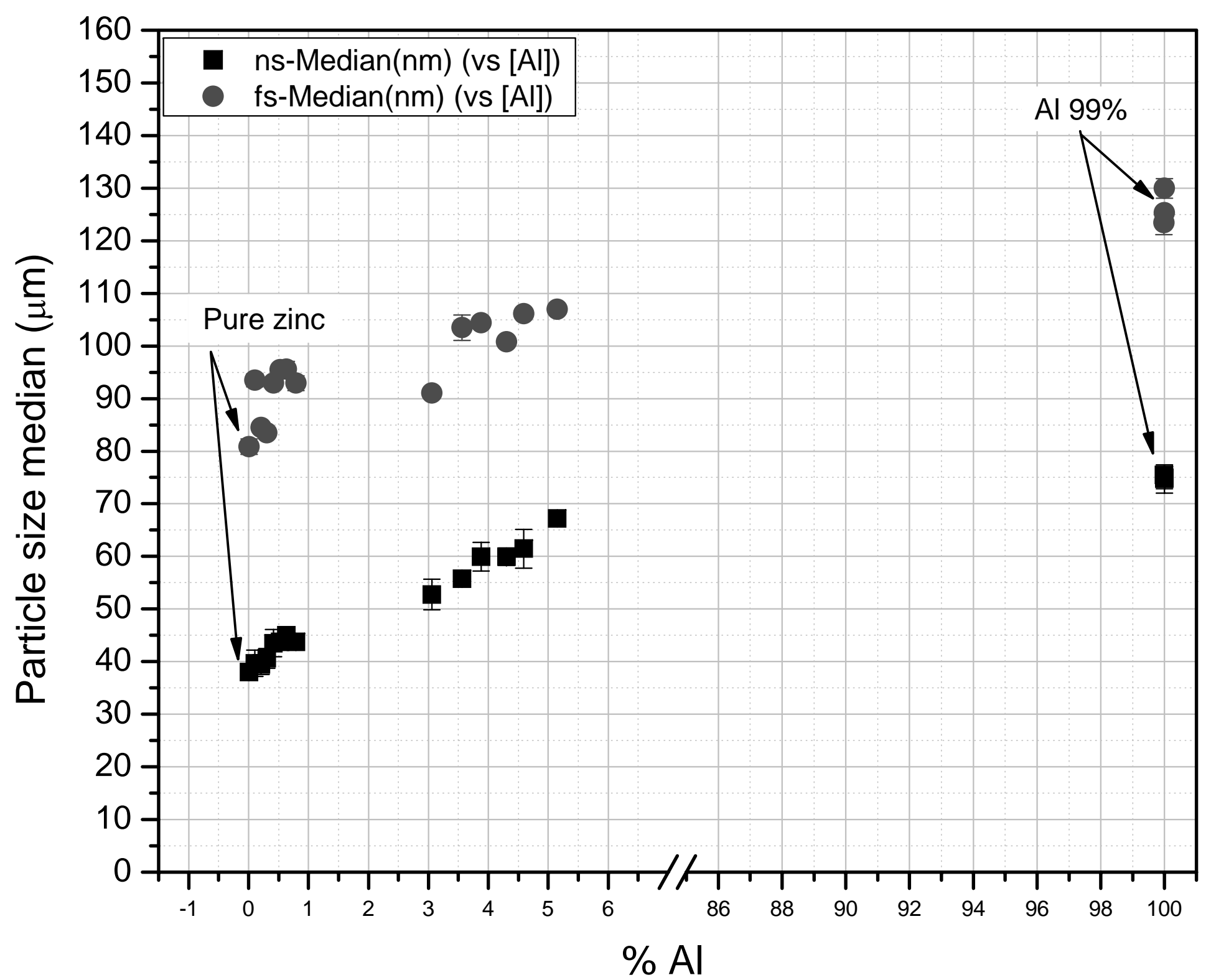

Figure 8 


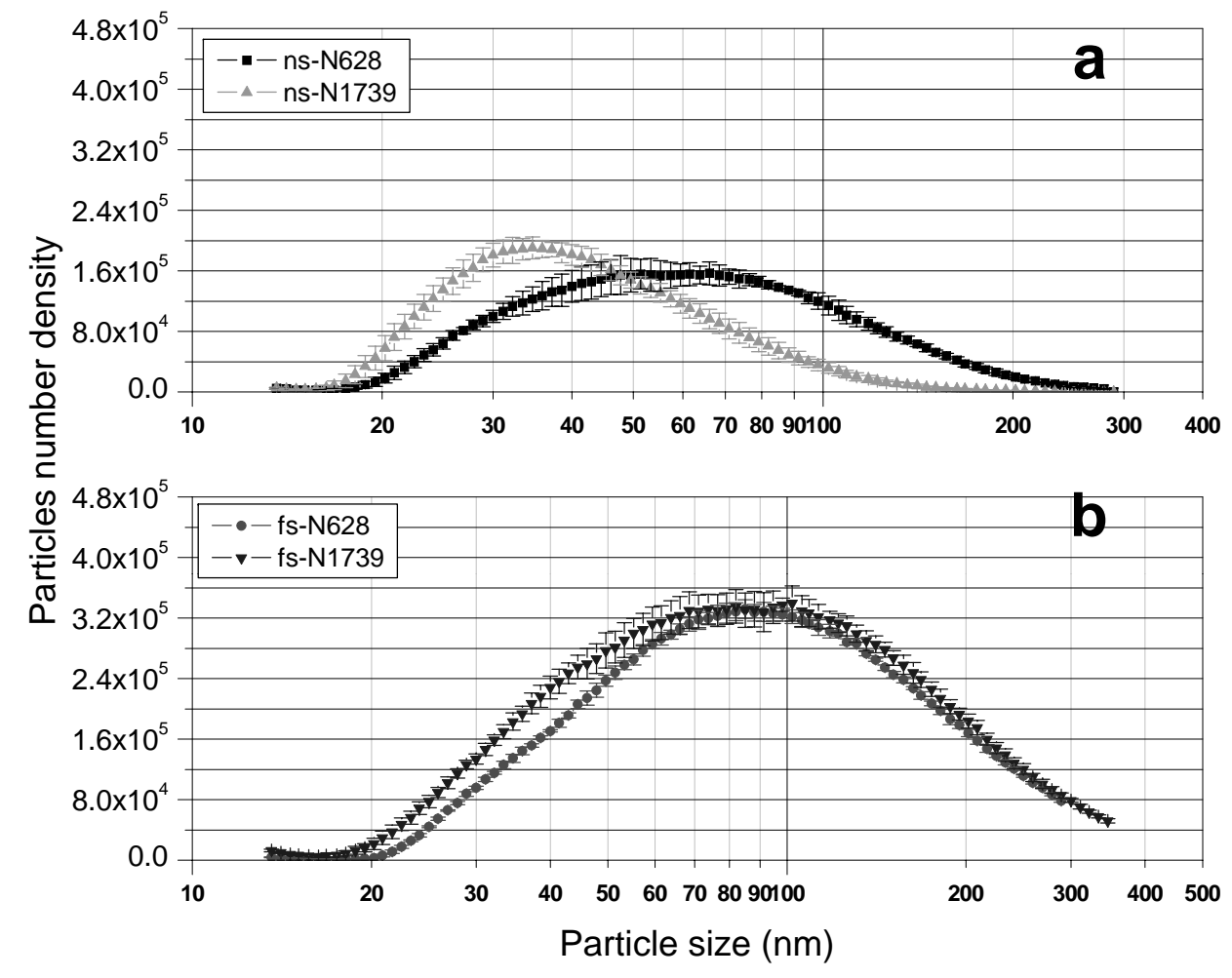

Calibration graphs for both series of standards using the nanosecond and femtosecond laser.

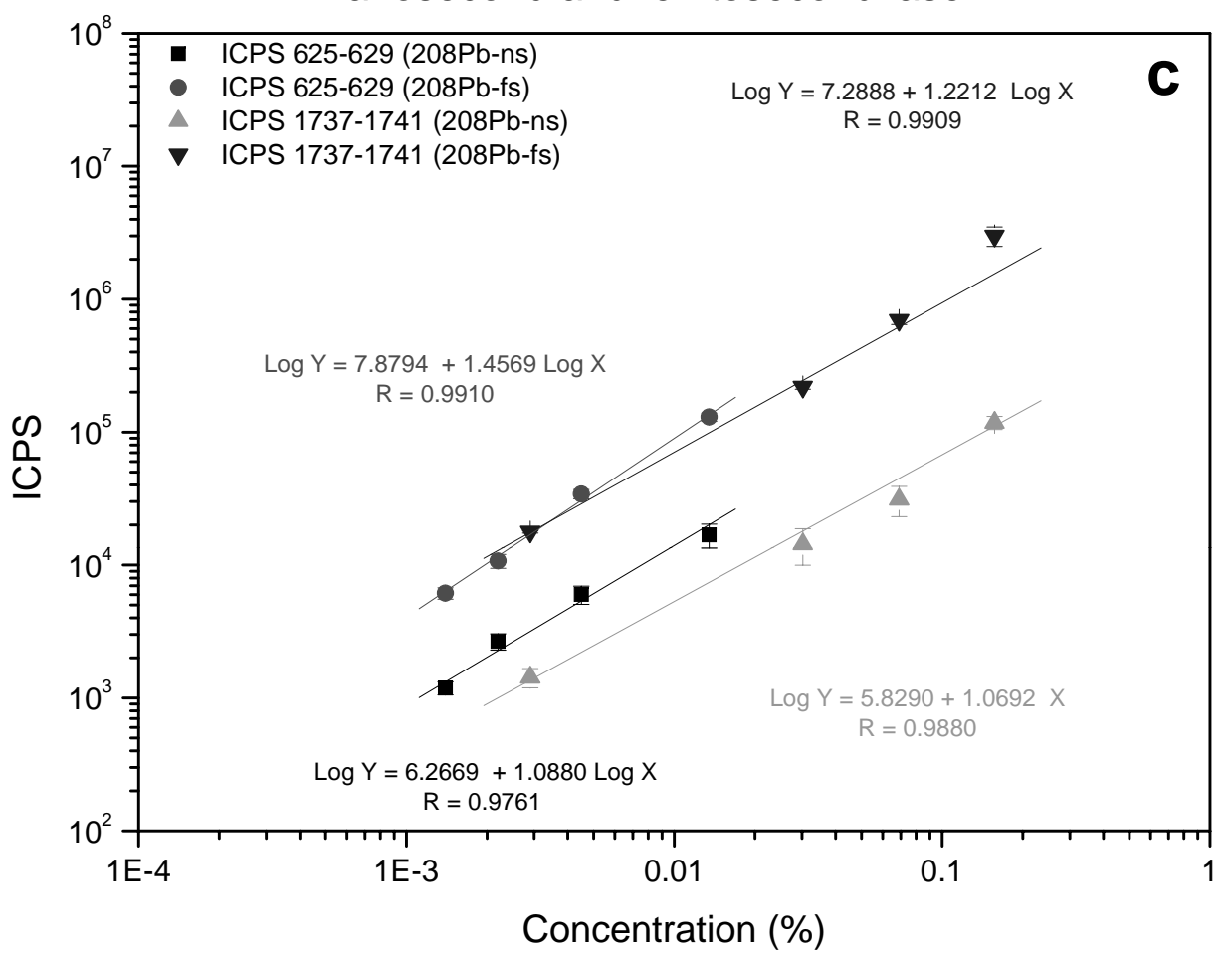

Figure 9 

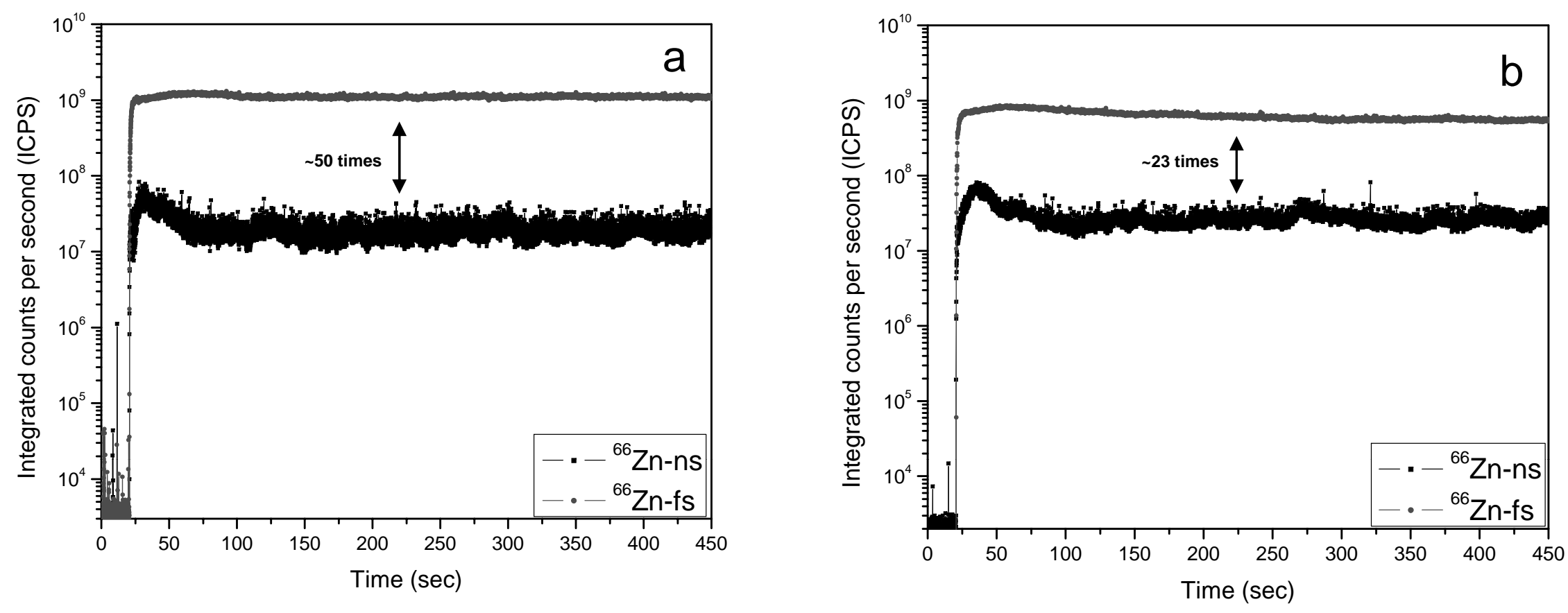

Figure 10 